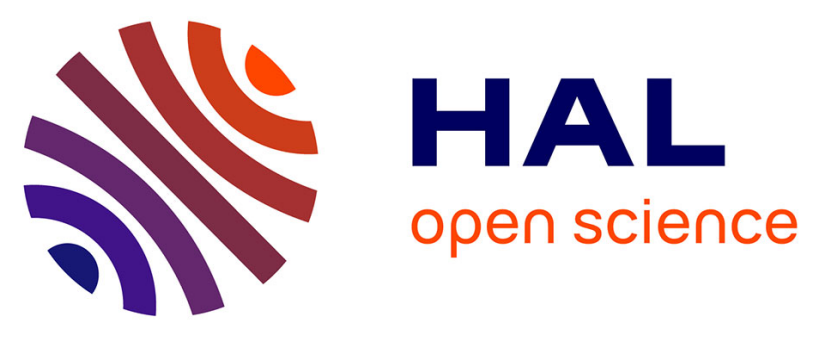

\title{
Disentangling the genetic origins of a plant pathogen during disease spread using an original molecular epidemiology approach
}

Constance Xhaard, Benoît Barres, Axelle Andrieux, Lydia Bousset, Fabien Halkett, Pascal Frey

\section{To cite this version:}

Constance Xhaard, Benoît Barres, Axelle Andrieux, Lydia Bousset, Fabien Halkett, et al.. Disentangling the genetic origins of a plant pathogen during disease spread using an original molecular epidemiology approach. Molecular Ecology, 2012, 21 (10), pp.2383-2398. 10.1111/j.1365-294X.2012.05556.x . hal-01191214

\author{
HAL Id: hal-01191214 \\ https://hal.science/hal-01191214
}

Submitted on 1 Sep 2015

HAL is a multi-disciplinary open access archive for the deposit and dissemination of scientific research documents, whether they are published or not. The documents may come from teaching and research institutions in France or abroad, or from public or private research centers.
L'archive ouverte pluridisciplinaire HAL, est destinée au dépôt et à la diffusion de documents scientifiques de niveau recherche, publiés ou non, émanant des établissements d'enseignement et de recherche français ou étrangers, des laboratoires publics ou privés. 


\title{
Disentangling the genetic origins of a plant pathogen during disease spread using an original molecular epidemiology approach
}

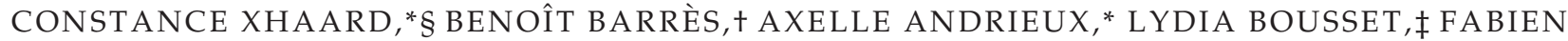 \\ HALKETT* and PASCAL FREY* \\ *INRA, Université de Lorraine, UMR1136 Interactions Arbres - Microorganismes, F-54280 Champenoux, France, +INRA, \\ Univ. Bordeaux, UMR1202 BIOGECO, F-33610 Cestas France, łINRA, Agrocampus Ouest, Université Rennes 1, UMR1349 \\ Institut de Génétique, Environnement et Protection des Plantes, F-35653 Le Rheu, France
}

\begin{abstract}
The advent of molecular epidemiology has greatly improved our ability to identify the population sources and track the pathogen movement. Yet the wide spatial and temporal scales usually considered are useful only to infer historical migration pathways. In this study, Bayesian genetic assignments and a landscape epidemiology approach were combined to unravel genetic origin and annual spread during a single epidemic of a plant pathogen: the poplar rust fungus Melampsora larici-populina. The study focused on a particular area-the Durance River valley-which enabled inoculum sources to be identified and channelled spread of the epidemic along a one-dimensional corridor. Spatio-temporal monitoring of disease showed that the epidemic began in the upstream part of the valley and spread out downstream. Using genetic assignment tests, individuals collected at the end of the epidemic were sorted into two genetic groups; very few hybrids were detected, although individuals from both groups coexisted locally downstream in the valley. The epidemic originated from two genetically distinct inoculum sources. Individuals of each group then dispersed southwards along the Durance River and became mixed in poplar riparian stands. These two genetic groups were found previously at a wider spatial scale and proved to result from distinct evolutionary histories on either wild or cultivated poplars. This study showed that the two groups can mix during an epidemic but do not hybridize because they then reproduce asexually. In general, the methods employed here could be useful for elucidating the genetic origin and retracing the colonization history and migration pathways of recent epidemics.
\end{abstract}

Keywords: biological invasions, emerging diseases, gene flow, landscape epidemiology, Melampsora larici-populina, poplar rust fungus

Received 28 September 2011; revision received 26 December 2011; accepted 10 January 2012

\section{Introduction}

Tracking pathogen movement, identifying source populations and understanding environmental factors (including human activities) that influence pathogen

Correspondence: Pascal Frey, Fax: +33 3833940 69; E-mail: frey@nancy.inra.fr

§Present address: INRA, UR546 Biostatistique et Processus Spatiaux, F-84914 Avignon Cedex, France.

१These authors codirected this work. spread are central tasks in disease ecology (Milgroom \& Peever 2003; Ostfeld et al. 2005; Archie et al. 2009). The advent of molecular biology has afforded new opportunities in the field of epidemiology (Milgroom 2001). In particular, molecular markers have greatly improved our ability to infer the dispersal routes of pathogens-at the very least corroborating previous classical surveys but most often providing additional clues as to the epidemiological history of disease progression (Milgroom \& Peever 2003; de Meeûs et al. 2007; Archie et al. 2009). 
Studies on the historical spread of pathogens often rely on phylogeographical analyses (Criscione et al. 2005; Archie et al. 2009; Estoup \& Guillemaud 2010), the main aims of which are to (i) highlight the centres of disease origin (e.g. Gómez-Alpizar et al. 2007; Kauserud et al. 2007; Stukenbrock et al. 2007; Gladieux et al. 2008) and (ii) infer the domestication routes of plant pathogens (Hovmøller et al. 2008; Munkacsi et al. 2008; Zaffarano et al. 2008; Gladieux et al. 2010). These classical studies hence provide accurate and valuable information that has helped to unravel the evolutionary history of various diseases. However, they may be less relevant to the design of current management policies. In particular, because they focus on very large temporal and spatial scales, such phylogeographical analyses can decipher only historical migration pathways, and they provide little information on the origin and spread of pathogens during current epidemics (Milgroom \& Peever 2003; Archie et al. 2009).

Many plant pathogens experience yearly extensive fluctuations in population size and geographical range (Burdon et al. 1989). This is especially true for crop pathogens in temperate climates. Plant disease epidemics collapse annually because of host senescence (e.g. leaf fall) or crop harvest, and recur the following year when conditions again become favourable (Mundt et al. 2011). These 'boom and bust' cycles have important consequences for the population genetics of plant pathogens, in terms of both spatial and temporal genetic differentiation (Bucheli et al. 2001; Zeller et al. 2004). In addition to classical founder effects linked to colonization events (Carlier et al. 1996; Barrès et al. 2008; Halkett et al. 2010), some of this temporal and spatial genetic differentiation can also result from the nonrandom recruitment of colonizing genotypes from different source populations (Burdon et al. 1989; Criscione et al. 2011). In the context of large demographic fluctuations and complex life histories, defining a priori exactly what the parasite population is (i.e. as a homogeneous genetic entity) is a challenging task (Waples \& Gaggiotti 2006; Barrett et al. 2008) requiring the disentangling of two processes: pathogen dispersal from inoculum sources, and population genetic mixing during the course of an epidemic. A major impediment to defining pathogen populations is the difficulty of appropriately combining population genetics analyses and epidemiological surveys at a common (hence local) spatial scale. Such molecular epidemiology analysis is required because the timescale considered is too short to accurately decipher dispersal pathways from molecular data only (no accumulation of mutations). As a consequence, the coalescent theory used in phylogeography studies no longer applies at such temporally and spatially restricted scales (Wang 2010). Instead, Bayesian assignment algorithms (Pritchard et al. 2000), which are designed to cluster individuals into homogeneous genetic groups, can be used to delineate pathogen populations, infer the source population of parasites and quantify the gene flow between populations (Waples \& Gaggiotti 2006; Archie et al. 2009). Assignment tests became tremendously popular (Kaeuffer et al. 2007), especially with the increasing availability of molecular markers such as microsatellite markers and high-quality genetic data sets, which enable well-resolved multilocus genotypes to be obtained and hence cryptic population structure to be assessed (Criscione et al. 2011; Xhaard et al. 2011). However, whether such assignment tests provide additional value in deciphering pathogen genetic structure resulting from a single epidemic remains to be tested.

A second challenge stems from the fact that following pathogen spread at a landscape scale is a difficult task (Holdenrieder et al. 2004; Plantegenest et al. 2007). In this study, we aimed to benefit from the specificities of a given pathogen life cycle (host alternation) to more easily monitor an epidemic. Host-alternating pathogens switch host species to complete their life cycle, performing their annual sexual reproduction stage on the alternate host and then multiplying asexually on the primary host for several months. It is this asexual multiplication on the primary host that causes the epidemics. Host alternation is common among rust fungi (Pucciniales) (Agrios 2005). In this type of life cycle, the starting point of a recurrent annual epidemic is defined by locations where the two hosts live in sympatry (Bourassa et al. 2007). Provided the geographical distributions of the hosts are known and restricted, it is possible to document the spread of disease on the primary host from starting points located in the sympatry area (Zogg 1949).

The present study focused on the poplar rust fungus Melampsora larici-populina, which infects poplar (Populus sp.), the primary (or telial) host, and larch (Larix sp.), the alternate (or aecial) host. The advantages of focusing on this species are twofold: first, the ecology and distribution areas of the two hosts are well known (Riou-Nivert 2001; Imbert \& Lefevre 2003; Pinon \& Frey 2005) and, second, cryptic population genetic structures in this fungal species have been evidenced recently (Xhaard et al. 2011). The Eurasian black poplar, Populus nigra, is a pioneer tree species of riparian forests that is distributed widely across Europe and Asia (Imbert \& Lefevre 2003). In Europe, wild poplar populations coexist with cultivated stands (Pinon \& Frey 1997). Many poplar cultivars carry qualitative resistance genes selected for their resistance to rust attack. Conversely, qualitative resistance has not been detected so far in P. nigra (Legionnet et al. 1999; Pinon \& Frey 2005). 
Cultivated poplars thus exert a strong and specific selective pressure on M. larici-populina individuals, and only those carrying the virulence corresponding to a given resistance gene can infect resistant hosts (Gérard et al. 2006). Evolving according to the gene-for-gene relationship (Flor 1971), M. larici-populina populations have overcome all the qualitative resistances deployed to date in poplar cultivation (Pinon \& Frey 2005). Consistently, Xhaard et al. (2011) demonstrated recently that poplar rust populations have been greatly impacted by poplar domestication. A cryptic population genetic structure was revealed at a regional scale, with three genetic groups displaying contrasting genetic signatures. The most abundant group ('cultivated' group) showed the hallmarks of a history of strong selection by host resistance and subsequent changes in demography. The second group ('wild' group) was closer to genetic equilibrium, in accordance with long-standing co-evolution with the wild host. A third group ('asexual' group) was shown to result from asexual overwintering of the fungus. Although the 'cultivated' and 'wild' genetic groups prevail in distinct geographical areas, they were also found mixed in some locations at the end of epidemics. These cases of local coexistence are all the more puzzling because very few hybrids were found. The present study tested the hypothesis that such local mixtures result from the gathering together of poplar rust genotypes during the course of epidemics on the primary host.

A study area-the Durance River valley located in the French Alps (Fig. 1)—was chosen that allows easy completion of the $M$. larici-populina life cycle and accurate monitoring of successive epidemic stages. The Dur- ance River flows north to south and is bordered by a nearly continuous riparian forest of wild poplar (P. nigra) of between 0.5 and $2 \mathrm{~km}$ wide. The upstream part of the valley encompasses part of the native range of European larch, Larix decidua (i.e. the 'Mélézin' in the central Alps, Riou-Nivert 2001). The presence of larch is restricted to the northern part of the area. This poplarlarch sympatry area restricts the sexual reproduction of M. larici-populina to this zone, which was thus postulated to be the starting point of the annual poplar rust epidemic (Frey et al. 2005). The annual asexual epidemic on poplars is assumed to spread southwards through the riparian stands of wild poplars, channelled along the river by the reliefs bordering the valley.

Hence, the Durance River valley constitutes a onedimensional ecological corridor in which epidemics of M. larici-populina are constrained, thus facilitating monitoring of their course. This simple ecological design is somewhat complicated by the presence of some cultivated poplar stands in both the sympatry and allopatry areas. On wild poplars, 'wild' and 'cultivated' groups of M. larici-populina were found to be segregated spatially in the northern part of the study area (i.e. in the area of poplar-larch sympatry) (Xhaard et al. 2011). Assuming that different foci in the poplar-larch sympatry area exist, these two groups can act as different population sources for the epidemic that spreads each year along the Durance River. In the time-course of an epidemic, it was thus suspected that southern poplar stands could become colonized by individuals with different genetic profiles, leading to the genetic mixture observed (Xhaard et al. 2011). Conversely, if the 'asexual' group contributes significantly to the inoculum

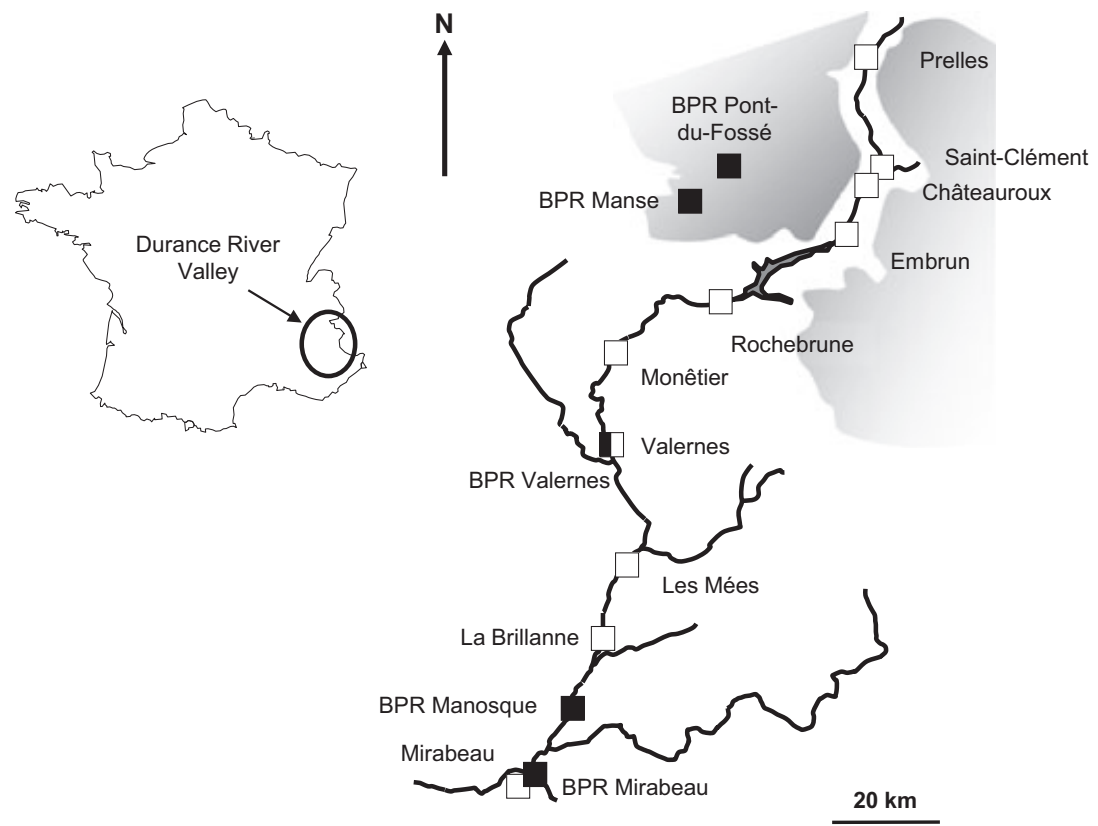

Fig. 1 Schematic representation of the Durance River valley. The grey areas at the top right of the figure represent the poplar-larch sympatry area where sexual reproduction of Melampsora laricipopulina takes place. Black and white boxes indicate the location of the cultivated and the wild stands studied, respectively. 
source, then the poplar rust epidemic would develop simultaneously all along the valley, and no pattern of spatio-temporal disease progression would be expected.

In this study, disease progression was monitored and the genetic profiles of M. larici-populina individuals collected along the Durance River valley at the end of the annual epidemic were analysed. The aim was to disentangle the genetic origins of this poplar rust epidemic. The hypothesis that two source populations contribute to the epidemic was tested, and the level of genotype mixing along the Durance River was assessed. To achieve this aim, both selected (virulence) and neutral (microsatellites) markers were used, and genetic partition of M. larici-populina individuals was tested using several Bayesian assignment tests.

\section{Materials and methods}

\section{Site monitoring and sampling details}

The sampling area is a corridor (c. $200 \mathrm{~km}$ long) in the Durance River valley in the French Alps (Fig. 1). Fifteen sites along or near the Durance River were sampled: 10 wild stands of Populus nigra and five cultivated stands containing the hybrid poplar P. $\times$ interamericana 'Beaupré', from which individuals were sampled (Table 1). Distances between contiguous sampled sites ranged from 5 to $32 \mathrm{~km}$. Two sampled cultivated stands and four wild stands were located within the poplarlarch sympatry area in the upstream part of the river
(Fig. 1). Two other cultivated stands were located in the vicinity of sampled wild stands (Valernes and Mirabeau) in the allopatry area (without larch).

The presence of disease symptoms (rust pustules) was monitored for both wild and cultivated sites every 3 weeks between July and October 2004. Hence, the date of first detection of rust symptoms was known for each site. Because the incidence of rust is generally lower in wild than in cultivated stands (Prakash \& Thielges 1987; Chen \& Harrington 2006), individuals from the wild sites were all collected at the same time in October, at the end of the epidemic. The incidence of rust is much higher in cultivated stands and can lead to early defoliation (Gérard et al. 2006). Therefore, the five cultivated sites were sampled between July and October, depending on local disease incidence. Infected leaves were collected on $P$. nigra in the wild sites and on P. $\times$ interamericana 'Beaupré' in the cultivated stands. To avoid resampling of clonal replicates, each individual was isolated from a distinct leaf collected from different trees and twigs. Whenever possible, 100-110 leaves were collected randomly for each wild site from up to 50 trees. The very focal infection at Valernes allowed the collection of only 30 leaves from five trees. The infection level of $P$. nigra trees at Saint-Clément, Châteauroux, La Brillanne and Mirabeau was also very low, even at the end of the epidemic, and only 10, 18, 22 and 5 infected leaves were collected from each of these sites, respectively. In cultivated stands, about 30 infected leaves were collected from 20 to 30 trees. The

Table 1 Characteristics of collection sites from wild and cultivated poplar stands and rust disease monitoring (1, rust detected and 0 , no rust detected)

Detection of rust symptoms

Collection site $\quad$ Latitude Longitude Host plant 7 July 28 July 18 August 8 September 29 September 13 October

\begin{tabular}{|c|c|c|c|c|c|c|c|c|c|}
\hline \multicolumn{10}{|l|}{ Wild stands } \\
\hline Prelles & $44^{\circ} 51^{\prime} 00^{\prime} \mathrm{N}$ & $6^{\circ} 34^{\prime} 47^{\prime} \mathrm{E}$ & Populus nigra & 1 & 1 & 1 & 1 & 1 & 1 \\
\hline Saint-Clément & $44^{\circ} 39^{\prime} 04^{\prime} \mathrm{N}$ & $6^{\circ} 35^{\prime} 09^{\prime} \mathrm{E}$ & P. nigra & 0 & 0 & 0 & 1 & 1 & 1 \\
\hline Châteauroux & $44^{\circ} 37^{\prime} 18^{\prime} \mathrm{N}$ & $6^{\circ} 32^{\prime} 47^{\prime} \mathrm{E}$ & P. nigra & 0 & 1 & 1 & 1 & 1 & 1 \\
\hline Embrun & $44^{\circ} 33^{\prime} 37^{\prime} \mathrm{N}$ & $6^{\circ} 30^{\prime} 42^{\prime} \mathrm{E}$ & P. nigra & 0 & 0 & 1 & 1 & 1 & 1 \\
\hline Rochebrune & $44^{\circ} 27^{\prime} 36^{\prime} \mathrm{N}$ & $6^{\circ} 11^{\prime} 55^{\prime} \mathrm{E}$ & P. nigra & 1 & 0 & 1 & 1 & 1 & 1 \\
\hline Monêtier & $44^{\circ} 22^{\prime} 50^{\prime} \mathrm{N}$ & $5^{\circ} 56^{\prime} 43^{\prime} \mathrm{E}$ & P. nigra & 0 & 0 & 1 & 1 & 1 & 1 \\
\hline Valernes & $44^{\circ} 14^{\prime} 54^{\prime} \mathrm{N}$ & $5^{\circ} 55^{\prime} 18^{\prime} \mathrm{E}$ & P. nigra & 0 & 0 & 0 & 0 & 1 & 1 \\
\hline Les Mées & $44^{\circ} 02^{\prime} 05^{\prime} \mathrm{N}$ & $5^{\circ} 57^{\prime} 52^{\prime} \mathrm{E}$ & P. nigra & 1 & 1 & 1 & 1 & 1 & 1 \\
\hline La Brillanne & $43^{\circ} 55^{\prime} 21^{\prime} \mathrm{N}$ & $5^{\circ} 53^{\prime} 60^{\prime} \mathrm{E}$ & P. nigra & 0 & 0 & 0 & 0 & 1 & 1 \\
\hline Mirabeau & $43^{\circ} 41^{\prime} 26^{\prime} \mathrm{N}$ & $5^{\circ} 40^{\prime} 22^{\prime} \mathrm{E}$ & P. nigra & 0 & 0 & 0 & 0 & 0 & 1 \\
\hline \multicolumn{10}{|l|}{ Cultivated stands } \\
\hline BPR Pont-du-Fossé & $44^{\circ} 40^{\prime} 28^{\prime} \mathrm{N}$ & $6^{\circ} 13^{\prime} 59^{\prime} \mathrm{E}$ & Beaupré & 1 & 1 & 1 & 1 & 1 & 1 \\
\hline BPR Manse & $44^{\circ} 37^{\prime} 11^{\prime} \mathrm{N}$ & $6^{\circ} 08^{\prime} 04^{\prime} \mathrm{E}$ & Beaupré & 0 & 0 & 1 & 1 & 1 & 1 \\
\hline BPR Valernes & $44^{\circ} 14^{\prime} 58^{\prime} \mathrm{N}$ & $5^{\circ} 55^{\prime} 20^{\prime} \mathrm{E}$ & Beaupré & 0 & 0 & 0 & 1 & 1 & 1 \\
\hline BPR Manosque & $43^{\circ} 48^{\prime} 57^{\prime} \mathrm{N}$ & $5^{\circ} 48^{\prime} 59^{\prime} \mathrm{E}$ & Beaupré & 0 & 0 & 0 & 1 & 1 & 1 \\
\hline BPR Mirabeau & $43^{\circ} 42^{\prime} 31^{\prime} \mathrm{N}$ & $5^{\circ} 42^{\prime} 56^{\prime} \mathrm{E}$ & Beaupré & 0 & 0 & 0 & 1 & 1 & 1 \\
\hline
\end{tabular}


high infection level in cultivated stands (which are never sprayed with fungicide against rust) ensures easy collection of infected leaves, except in Manosque where only eight infected leaves were collected.

\section{Isolation of individual genotypes}

One single uredinium (sporulating lesion of Melampsora larici-populina producing urediniospores) per leaf was selected randomly and grown on fresh leaf discs of P. $\times$ euramericana 'Robusta' as described by Barrès et al. (2008). Mono-uredinial isolation ensures that a single genotype per sampled leaf is isolated and multiplied, so that both virulence phenotype assessment and molecular characterization can be performed on the same individual genotype.

\section{Assessment of virulence profiles}

All M. larici-populina individuals were inoculated on two poplar cultivars: one susceptible cultivar $(P . \times$ euramericana 'Robusta') and the second carrying the R7 rust resistance $(P . \times$ interamericana 'Beaupré'), as described by Barrès et al. (2008). The success of the differential infection revealed the virulence phenotype, denoted Vir7 if both resistant and susceptible leaf discs were infected, and Avr7 if only susceptible (control) leaf discs were infected. After virulence scoring, leaf discs of 'Robusta' were stored at $-20{ }^{\circ} \mathrm{C}$ until DNA extraction.

\section{Microsatellite analysis}

When more than 50 individuals per site were available, a subset of only 48 individuals was selected randomly for DNA analyses. Otherwise, all individuals were retained (Table 2). DNA was extracted using a DNeasy ${ }^{\circledR} 96$ Plant kit (Qiagen, Hilden, Germany) as described in the study by Barrès et al. (2006). Microsatellite analyses were performed at 26 polymorphic loci: $\mu$ MLP09, $\mu$ MLP12, $\mu \mathrm{MLP} 22, \mu \mathrm{MLP} 27, \mu \mathrm{MLP} 28, \mu \mathrm{MLP} 30$ and $\mu \mathrm{MLP} 31$ (Barrès et al. 2006); MLP49, MLP50, MLP54, MLP55, MLP56, MLP57, MLP58, MLP61, MLP66, MLP68, MLP74, MLP77, MLP81, MLP82, MLP87, MLP91, MLP92, MLP96 and MLP97 (Xhaard et al. 2009). The same PCR protocol as described in the study by Xhaard et al. (2009) was followed except that a Qiagen ${ }^{\circledR}$ Multiplex PCR kit was used and the forward primers were labelled with three different dyes: D2, D3 and D4 (Proligo), according to the Beckman tagging technology manual. Three multiplex PCR were run, the first with 12 loci (D2: MLP49, MLP54, MLP56, MLP66 and MLP77; D3: MLP57, MLP61, MLP68 and MLP87; D4: MLP50, MLP55 and MLP97), the second with six loci (D2: $\mu$ MLP22 and $\mu$ MLP27; D3: $\mu$ MLP28 and $\mu \mathrm{MLP30}$; 4 : $\mu$ MLP09 and $\mu$ MLP12) and the third with eight loci (D2: MLP58, MLP74 and MLP82; D3: $\mu$ MLP31, MLP81 and MLP92; D4: MLP91 and MLP96). PCR products were separated, sized and analysed on a CEQ8000 Genetic Analysis System (Beckman Coulter).

\section{Analysis of genetic data}

Identification of repeated multilocus genotypes. Data were checked for misprint and scoring errors using MicroCHeCKer software (Van Oosterhout et al. 2004). Identical genotypes were identified and tested further using MLgsim software (Stenberg et al. 2003) to determine whether individuals with identical multilocus genotype were indeed true clones. First, the probability of observing a multilocus genotype $n$ times in a population was computed. Second, using a Monte Carlo simulation method, the program determines the significance threshold for the probability values, indicating the multiple copies of the same multilocus genotype that did not occur by chance (true clones). Calculations took into account the population size and allele frequencies.

In order to minimize departure from Hardy-Weinberg (HW) expectations and linkage disequilibrium (LD), on which several analyses are based, only one copy of each multilocus genotype (found to be significantly over-represented) was considered for all subsequent genetic analyses.

Standard population genetics analysis. Standard population genetics analyses were carried out before Bayesian assignment tests on each sampled location, and after Bayesian assignment tests on each genetic group, to further assess their characteristics. Expected and observed heterozygosities were calculated using GENETIX (4.05) (Belkhir et al. 1996-2004). As the observed number of alleles in a sample is highly dependent on sample size, allelic richness $\left(A_{r}\right)$ was calculated using FstAT version 2.9.3 (Goudet 1995). F-statistics were computed using FsTAT according to Weir \& Cockerham (1984). The level of LD between loci was measured by the multilocus estimate disequilibrium $\left(\bar{r}_{D}\right)$ based on the index of association corrected for the number of loci (Agapow \& Burt 2001). Deviations from HW expectations (heterozygote excess and deficit) were calculated using GENEPOP on the web (http://genepop.curtin.edu.au/) (Rousset 2008). In order to adjust the $P$-values for multiple tests for LD, the false discovery rate (FDR) procedure (Benjamini \& Yekutieli 2001) was used, which controls for the proportion of significant results (FDR) instead of controlling for the chance of making even a single error. The resulting adjusted $P$-values are called $Q$ values. This procedure is implemented in the $\mathrm{R}$ package QVALUE (Storey \& Tibshirani 2003). Finally, the correlation between genotypic assignment results and phenotypic 
information was tested through a logistic regression between individual memberships and virulence profiles (Boolean data, 1 for Vir7 and 0 for Avr7 individuals).

Population structure and Bayesian assignment analysis. The genetic differentiation between individuals was first visualized with a correspondence analysis performed using Genetix (version 4.05) (Belkhir et al. 1996-2004). The partition of the data set into different genetic groups was further tested using Bayesian genetic assignment tests. Three different software products were used to check the consistency of the partitioning and the assignment results. First, Structure version 2.2 (Pritchard et al. 2000; Falush et al. 2003)—the reference software for such analyses (Evanno et al. 2005)—was used with the admixture model with correlated allele frequency and default settings. Iteration parameters were set to a burning-in period of 30000 iterations followed by 1200000 iterations. The likelihood of the assignments $[\ln P(\mathrm{D})]$ was evaluated for $K$ (the number of genetic groups) varying from 1 to 10 . Three independent simulations were performed for each value of $K$ to test for consistency of results. To assess the value of $K$ that best explains the partitioning of the genetic data, the $\Delta K$ estimator was computed as described by Evanno et al. (2005).

Second, GenELAND (version 3.1.4) (Guillot et al. 2005b; Guillot 2008) was used, without including spatial information, to cross-validate the assignment procedure. The strength of this second method is that the best number of groups, $K$, is inferred during a single run (unlike in STRUCTURE) because of the specific Reverse Jump MCMC (Markov chain Monte Carlo) algorithm implemented, which enables the Markov chain to explore the whole range of putative cluster numbers at each step of the simulation. Hence, the number of groups that best explains the data is given by the dimension value (here the value of $K$ ) in which the Markov chain spent most iterations (Guillot et al. 2005a,b). The value of $K$ was allowed to vary from 1 to 10 and initialized at 8 . Once the most likely $K$ value was determined, additional runs were performed, with the corresponding value of $K$ fixed, to better infer the membership level of each individual to the $K$ groups, as advised in the study by Guillot et al. (2005b). For runs with varying $K$, the uncorrelated allele frequency model was used, and for those with fixed $K$, the correlated allele frequency model (Guillot 2008) with default settings was used, except for the number of nuclei, which, given the number of individuals, was increased to 500 (in the nonspatial mode). Iteration parameters were set to 550000 iterations with a burning-in period of 50000 iterations.

Finally, NewHYBRIDS (version 1.1), which implements a Bayesian genetic assignment approach dedicated to the quantification of hybridization events (Anderson \& Thompson 2002), was used. The detection of backcrosses requires many more loci (almost 50) than the 26 used here (Vaha \& Primmer 2006). We therefore focused on first-generation hybrids between parental classes. The Bayesian method allows either loading of prior knowledge of the allele frequencies of the parental classes or their estimation from the offspring genetic data set. Here, the program was used without any prior information. The following parameters were used: a short burn-in period of 1000 iterations, followed by 1000000 iterations. With each of the three Bayesian clustering methods, three independent runs were performed to check for consistency in the convergence of Markov chains. Whatever the method employed, the same threshold of membership coefficient $(q>0.9)$ was fixed for assigning individuals to a cluster.

Analysis of isolation by distance. Isolation by distance (IBD) was assessed within each genetic group (considering only locations with at least five assigned individuals) using the continuous method (Rousset 2000) of the 'Isolde' procedure implemented in GENEPOP (Rousset 2008; option 'Analysis of isolation by distance between groups'). The significance of Mantel tests between pairwise genetic distances [calculated as $F_{\mathrm{ST}} /\left(1-F_{\mathrm{ST}}\right)$ ratios] and geographical distances was determined using the ISOLDE program (10 000 permutations). For geographical distances, Euclidian distances between pairs of sampling sites were considered. It should be noted that the aim here was not to infer dispersal distance from the slope of the regression line, as this biological system does not meet the requirements of the IBD model (Rousset 1997). Instead, the aim was to decipher whether the observed variation in pairwise genetic distance is gradual (according to geographical distance) or random.

\section{Results}

Timing of disease progression along the Durance River valley

Poplar leaf infections were first detected at the beginning of summer in the upstream part of the valley, where larches grow in sympatry with poplar trees (Fig. 1 and Table 1). Other sites then became infected according to their location downstream in the valley, indicating that the epidemic begins in the upstream part of the valley and then spreads out downstream following the river. This spatio-temporal dynamic was particularly obvious with the wild sites. Nonetheless, there were two exceptions to this regular spread. Infection began very early in Les Mées, at the beginning of 
the survey period (7 July), although this site is located far from the poplar-larch sympatry area. Conversely, a late infection (8 September) was observed in Saint-Clément, although this site is located within the poplarlarch sympatry area. In the cultivated poplar stands, the epidemic also spread downwards through the valley. Nonetheless, the locations of the cultivated stands-two in the poplar-larch sympatry area in the north and the remaining three in the south part of the valley-did not allow proper quantification of disease progression (compared to the wild sites). Indeed, there was a notable discrepancy in the relative timing of infection between wild and cultivated stands as the latter became infected earlier in the downstream part of the valley (Table 1).

\section{Site-by-site virulence profiles}

The frequency of individuals carrying Vir7 virulence ranged from 0 to 1 across sampling sites, with a mean proportion of 0.33 (Table 2). All individuals collected on 'Beaupré' exhibited a Vir7 phenotype, as expected given the presence of the R7 resistance in this cultivar (Table 2). For individuals sampled on Populus nigra, the frequency of Vir7 ranged from $0 \%$ (Saint-Clément and Châteauroux) to $44 \%$ (Valernes; Table 2). Samples from the wild stands located in the upstream part of the valley (Prelles, Saint-Clément, Châteauroux and Embrun) exhibited a very low percentage (0-3\%) of Vir7 individuals. In contrast, the proportion of Vir7 individuals was much higher (17-44\%) in all wild sites further downstream in the Durance River valley, except in Les Mées (3\%) (Table 2).

\section{Overall genetic and genotypic diversity}

Of the 478 individuals genotyped, only eight were excluded from further analyses because they failed to amplify. The remaining 470 individuals exhibited only $0.6 \%$ missing data on average. All 26 microsatellite markers were highly polymorphic, with the number of alleles ranging from 4 to 19 (mean number across loci: 7.11).

Of the 470 individuals analysed, 331 distinct multilocus genotypes were found. All the repeated multilocus genotypes were found to be significantly over-represented according to the analysis performed using MLGsim. Repetitions of a given multilocus genotype were thus considered to result from clonal reproduction only and were further denoted as clonal copies. Repeated genotypes were found in both wild and cultivated stands (Table 2). Three repeated genotypes were each highly represented, with 34, 30 and 20 clonal copies. The remaining 29 repeated multilocus genotypes occurred in two to ten clonal copies. Almost all repeated genotypes were found within a single site, except for six repeated genotypes that were found at four distinct sites, with a maximal resampling distance of $126 \mathrm{~km}$. Among the wild stands, repeated genotypes predominated in the downstream region of the Durance River valley, especially in Les Mées and La Brillanne (Table 2).

The genetic diversity of Melampsora larici-populina samples was significantly higher among wild stands $\left(H_{\mathrm{E}}=0.474\right)$ compared to cultivated stands $\left(H_{\mathrm{E}}=0.403\right.$, $P<0.05)$. Focusing on the wild stands, the highest genetic diversity was found in the sympatry area at Prelles (Table 2). Significantly more heterozygotes were found in the sympatry area (Prelles to Embrun locations, $H_{\mathrm{O}}=0.475$ ) than in the allopatry area (Rochebrune to Mirabeau, $\left.H_{\mathrm{O}}=0.428, P<0.05\right)$. Conspicuously, the two uppermost sites among the wild and cultivated stands (Prelles and Pont-du-Fossé, respectively) were among the very few sites found to be in genetic equilibrium (both HW equilibrium and random association of alleles across loci, Table 2). Most wild stands displayed significant LD, which, together with high $F_{\text {IS }}$ values in the downstream part of the Durance River valley, could denote some genetic mixing (Wahlund effect).

\section{Genetic structure and assignment results}

Individual genotypes were separated largely according to their Vir7 or Avr7 profile in the correspondence analysis (Fig. 2). Most Vir7 individuals were clustered, regardless of their sampling origin (wild or cultivated stands). While the first axis differentiated individuals according to their Vir7/Avr7 profile, the second differentiated individuals collected mostly from wild sites. Thus, individuals from the cultivated stands were clumped together, in contrast to those from wild stands, which were much more scattered. However, the first two axes explained only $5.8 \%$ of the total inertia. The relevance of such a genetic structure among sampled individuals was therefore subsequently explored through Bayesian assignment tests.

All Bayesian assignment tests were conducted to include only one copy of each repeated multilocus genotype in order to minimize departure from the HW expectations on which the assignment procedures were based. Regardless of the method employed, Markov Chains converged rapidly, and the three replicate runs gave consistent results. The Structure and GENELAND algorithms were in agreement, both gathering individuals into two clusters (Table 3). However, GenELAnd seemed to perform better and gave clearer results: (i) Markov Chain for GENELAND runs settled rapidly on 
Table 2 Characteristics of Melampsora larici-populina individuals analysed from each location

\begin{tabular}{|c|c|c|c|c|c|c|c|c|c|c|}
\hline Collection site & $N_{\mathrm{P}}$ & Vir7 & $N_{\mathrm{G}}$ & G & $G / N_{\mathrm{G}}$ & $A_{r}^{+}$ & $H_{\mathrm{E}}^{+}$ & $H_{\mathrm{O}}^{+}$ & $F_{\mathrm{IS}}^{+}$ & $\bar{r}_{D}^{+}$ \\
\hline \multicolumn{11}{|l|}{ Wild stands } \\
\hline Prelles & 103 & 0.02 & 48 & 48 & 1.00 & 2.11 & 0.501 & 0.486 & 0.031 & 0.008 \\
\hline Saint-Clément & 10 & 0.00 & 10 & 10 & 1.00 & 2.02 & 0.467 & 0.484 & -0.040 & $0.065^{* * *}$ \\
\hline Châteauroux & 16 & 0.00 & 16 & 12 & 0.75 & 1.80 & 0.393 & 0.467 & $-0.197^{* *}$ & $0.731^{* * *}$ \\
\hline Embrun & 102 & 0.03 & 48 & 44 & 0.92 & 2.04 & 0.482 & 0.463 & 0.040 & $0.019^{* * *}$ \\
\hline Rochebrune & 84 & 0.42 & 46 & 39 & 0.85 & 2.03 & 0.484 & 0.431 & $0.110^{* * *}$ & $0.023^{* * *}$ \\
\hline Monêtier & 97 & 0.35 & 47 & 45 & 0.96 & 2.06 & 0.489 & 0.443 & $0.094^{* * *}$ & $0.038^{* * *}$ \\
\hline Valernes & 108 & 0.44 & 48 & 44 & 0.92 & 1.96 & 0.445 & 0.407 & $0.088^{* * *}$ & $0.049^{* * *}$ \\
\hline Les Mées & 108 & 0.03 & 48 & 13 & 0.27 & 1.98 & 0.459 & 0.439 & 0.045 & $0.156^{* * *}$ \\
\hline La Brillanne & 24 & 0.17 & 24 & 5 & 0.21 & 1.84 & 0.413 & 0.448 & -0.098 & $0.333^{* * *}$ \\
\hline Mirabeau & 5 & 0.40 & 5 & 5 & 1.00 & 1.89 & 0.413 & 0.370 & 0.116 & 0.020 \\
\hline \multicolumn{11}{|l|}{ Cultivated stands } \\
\hline BPR Pont-du-Fossé & 30 & 1.00 & 30 & 27 & 0.90 & 1.79 & 0.387 & 0.393 & -0.015 & 0.003 \\
\hline BPR Manse & 32 & 1.00 & 32 & 15 & 0.47 & 1.92 & 0.440 & 0.420 & 0.047 & $0.070^{* * *}$ \\
\hline BPR Valernes ${ }^{\ddagger}$ & 29 & 1.00 & 29 & 3 & 0.10 & - & - & - & - & - \\
\hline BPR Manosque & 9 & 1.00 & 9 & 8 & 0.89 & 1.83 & 0.403 & 0.400 & 0.008 & $0.047^{* *}$ \\
\hline BPR Mirabeau & 30 & 1.00 & 30 & 18 & 0.60 & 1.85 & 0.398 & 0.387 & 0.027 & 0.005 \\
\hline
\end{tabular}

$N_{\mathrm{P}}$, number of individuals phenotyped; Vir7, proportion of Vir7 individuals; $N_{\mathrm{G}}$, number of individuals genotyped; $G$, number of distinct genotypes; $G / N_{\mathrm{G}}$, genotypic richness; $A_{r}$, allelic richness, estimated for a sample size of three individuals; $H_{\mathrm{E}}$, unbiased estimate of gene diversity (Nei 1978); $H_{\mathrm{O}}$, observed heterozygosity; $F_{\mathrm{IS}}$, departure level and test of Hardy-Weinberg equilibrium; $\bar{r}_{D}$, multilocus estimate and test of linkage disequilibrium. Significant levels of $P$-values were corrected for multiple comparisons using false discovery rate (FDR) control $\left({ }^{*} Q\right.$ value $<0.05 ;{ }^{* *} Q$ value $<0.01 ;{ }^{* * *} Q$ value $<0.001$ ).

${ }^{\dagger}$ Measures of genetic diversity and genetic equilibrium tests were performed considering only one copy per repeated multilocus genotype.

${ }^{\ddagger}$ Genetic diversity indices and test of genetic equilibrium were not conducted on this site because the number of distinct genotypes was too small.

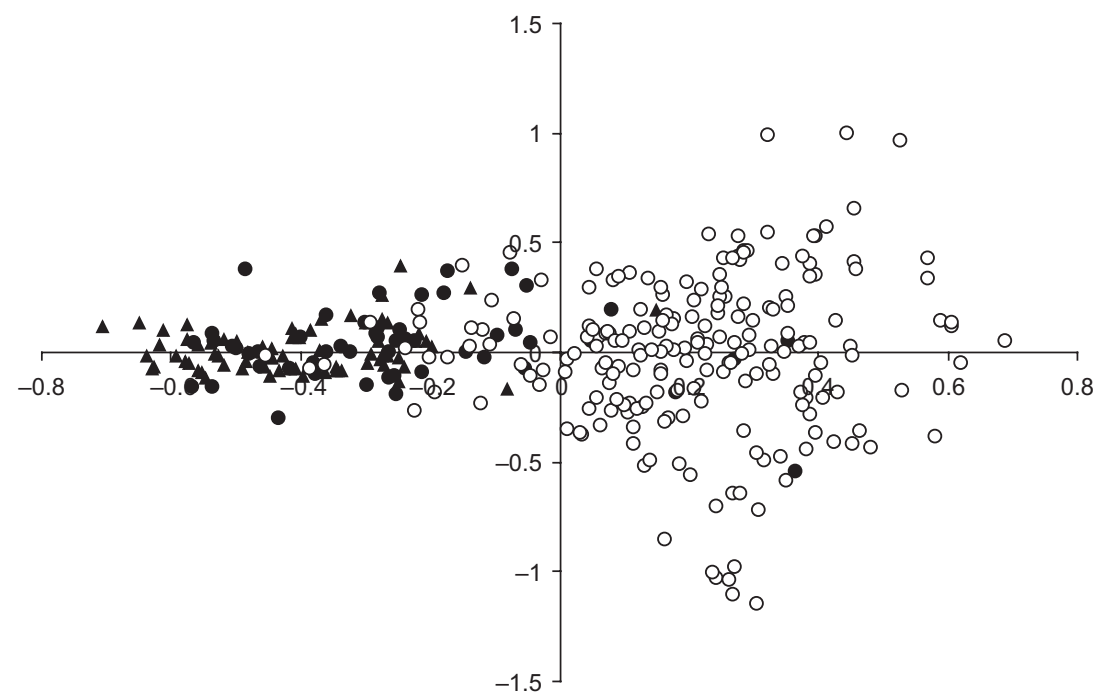

Fig. 2 Correspondence analysis performed with GeNETIX on the 331 multilocus genotypes of Melampsora larici-populina. $\Delta$ cultivated sites (Vir7 individuals), $\bigcirc$ wild sites (Avr7 individuals), $\bullet$ wild sites (Vir7 individuals).

$K=2$, whereas likelihood analysis using STRUCTURE runs showed bimodal values for the best number of clusters; and (ii) the assignment profile was more clear cut for GENELAND (Fig. 3). Applying an assignment coefficient of $q>0.9$ led to the exclusion of $93(28 \%)$ and $22(7 \%)$ individuals in STRUCTURE and GENELAND, respectively.
A second step further investigated whether the nonassigned individuals revealed by STRUCTURE and GENELAND could result from hybridization events between individuals of the two genetic clusters. Interestingly, the assignment profile obtained with NEwHYBRIDS was very close to that obtained with GENELAND (data not shown). In particular, similar membership values were observed 
Table 3 Inference of the number of cluster(s) $(K)$ that best explain the genetic structure among samples (tests performed with a single copy per repeated genotype). For STRUCTURE runs, the mean value of log likelihood across simulations was reported, and the $\Delta K$ index was computed according to Evanno et al. (2005). For Geneland runs, the proportion of iterations spent by the RJMCMC across simulation (after the burning period) is reported

\begin{tabular}{rlrl}
\hline & \multicolumn{2}{l}{ StRUCtURE } & \\
\cline { 2 - 3 }$K$ & Log likelihood & $\Delta K$ & GENELAND \\
\hline 1 & -16582 & & $\sim 0$ \\
2 & -15856 & 382 & $\sim 1$ \\
3 & -15512 & 176 & $\sim 0$ \\
4 & -15343 & 8 & $\sim 0$ \\
5 & -15182 & 31 & $\sim 0$ \\
6 & -14990 & 43 & $\sim 0$ \\
7 & -14840 & 113 & $\sim 0$ \\
8 & -14803 & 174 & $\sim 0$ \\
9 & -14592 & 225 & $\sim 0$ \\
10 & -14607 & 14 & $\sim 0$ \\
\hline
\end{tabular}

for individuals previously assigned (membership coefficient $q>0.9$ ) to the two clusters. Among the previously nonassigned individuals, a single multilocus genotype (occurring twice in the sample) was undisputedly a first-generation hybrid when considering the same

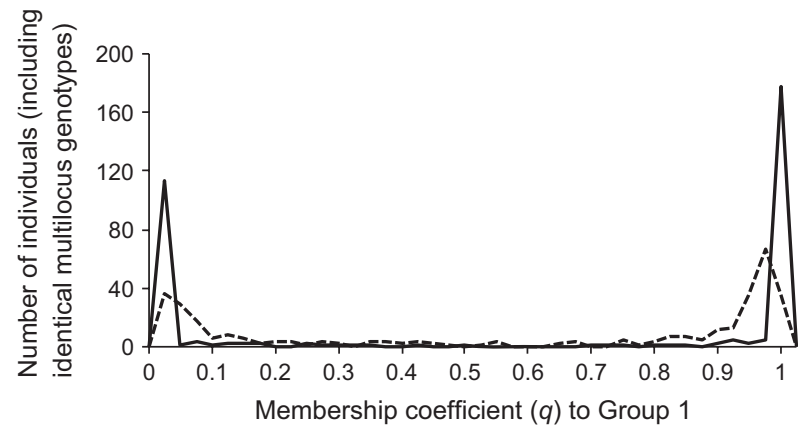

Fig. 3 Distribution of the mean value of the membership coefficient $(q)$ to the genetic group 1 ('cultivated' group) calculated over three simulation runs performed with GENELAND (solid curve) and with StRUCTURE (dashed curve) on the 331 multilocus genotypes of Melampsora larici-populina.

threshold of $q>0.9$. The other nonassigned individuals had varying proportions of their genome attributed to the hybrid and parental clusters (Fig. 4).

\section{Genetic and phenotypic characteristics of individuals from the two genetic groups}

In the following, we focus on results obtained with NEwHYBRIDS to further unravel the biological properties of the two genetic entities.

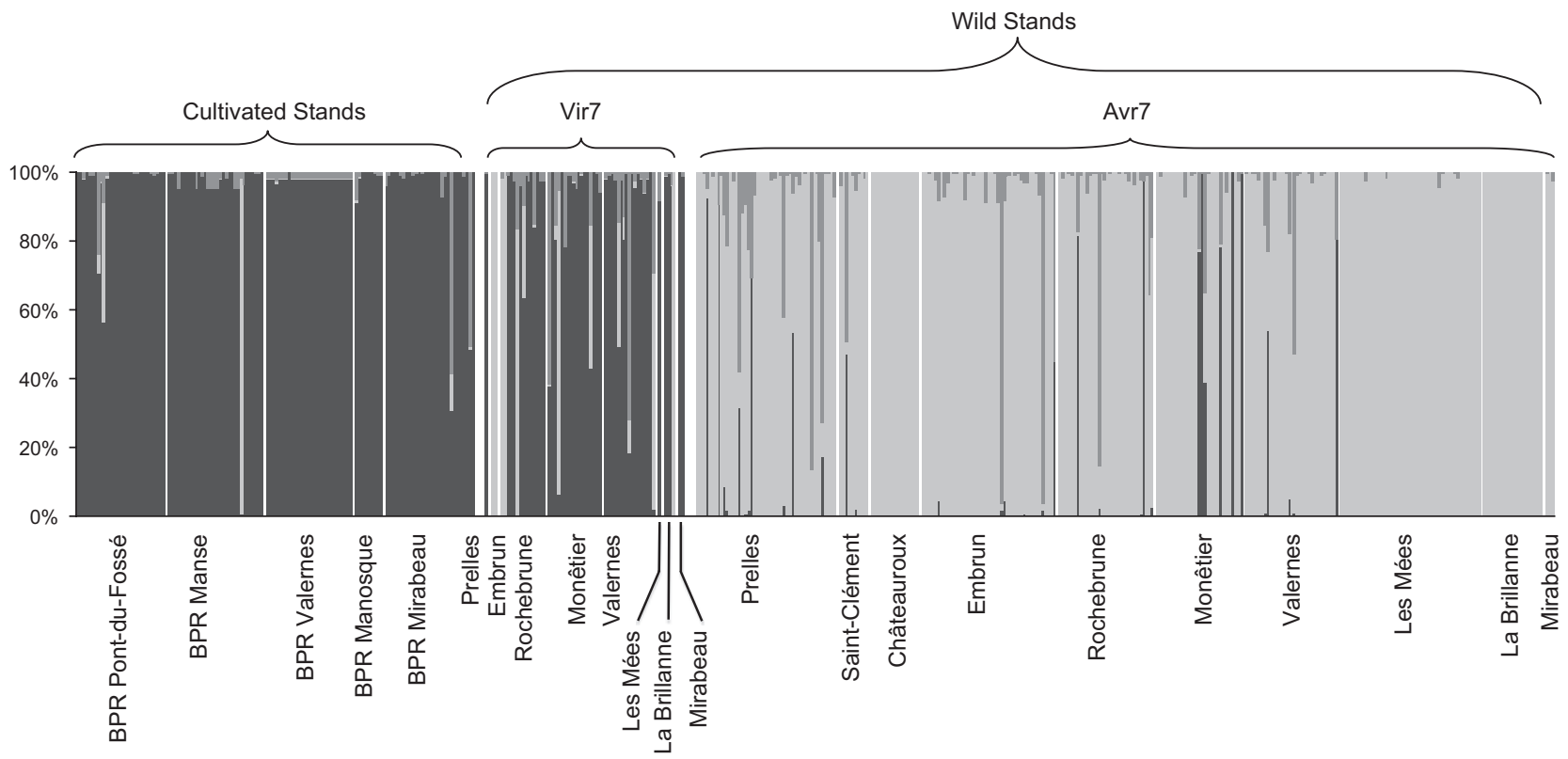

Fig. 4 Assignment profiles of the 470 Melampsora larici-populina individuals using NewHyBRIDs, including all copies of repeated genotypes. Individuals were sorted according to their sampling sites and virulence profile. Each vertical line represents an individual whose genome is partitioned into $K$ segments (here $K=2$ genetic groups, plus the first-generation hybrids). Segment lengths are proportional to the individual's mean membership coefficients in each genetic group. Black, light grey and dark grey segments correspond to genetic groups 1 and 2, and first-generation hybrids, respectively. White bars separate individuals sampled from different locations, as indicated underneath. 
Re-including clonal copies, and applying an assignment coefficient threshold of $q<0.9$, more than $93 \%$ of sampled individuals could be assigned, 251 belonging to the first genetic group and 174 to the second. There was a moderate, albeit significant, genetic differentiation level between the two groups $\left(F_{\mathrm{ST}}=0.094, P<0.05\right)$.

Interestingly, the distinction made according to virulence phenotype roughly matched a segregation in individual memberships: Vir7 individuals being assigned mostly to genetic group 1 and Avr7 individuals to genetic group 2 (Fig. 4). A highly significant correlation was found between individuals belonging to the first group and their virulence profile (logistic regression, $P<0.001)$. Exceptions to this rule included only three individuals (one from the cultivated stand of BPR Manse and two from the wild stand at Embrun). Reciprocally, five Avr7 individuals were assigned to group 1 (two from Prelles and three from Monêtier).

Comparison of genetic characteristics of individuals from the two groups revealed that-in several instances-individuals from group 1 were less genetically diverse than those from group 2. Values of all genetic diversity indices (observed and expected heterozygosity) were significantly lower for individuals from group 1 (Table 4). In addition, rare alleles occurred only among group 2 genotypes (data not shown). Groups 1 and 2 were thereafter referred to as 'cultivated' and 'wild' groups, respectively.

Spatial repartition of individuals belonging to 'wild' and 'cultivated' groups, and within-group genetic structure

A site-by-site examination of individual membership of the 'wild' and 'cultivated' genetic groups mirrors the spatial distribution of Vir7/Avr7 phenotypes presented above (Fig. 5). In particular, it is obvious that individuals from the two genetic groups can coexist locally in wild stands without detecting hybrids, whereas cultivated stands consist almost exclusively of individuals from the 'cultivated' group. In addition, 'cultivated' individuals are not distributed evenly among the wild sites: sites located in the northern part of the valley (Prelles, Saint-Clément, Châteauroux, Embrun) were almost free of 'cultivated' individuals (consisting mostly of Avr7 individuals), but the frequency of 'cultivated' (and thus Vir7) individuals increased abruptly when considering sites located downstream of the poplar-larch sympatry area (downstream of Rochebrune), reaching up to $44 \%$ of sampled individuals in Valernes (Fig. 5). The sole exception to this pattern was the site of Les Mées, where no 'cultivated' individuals were found.

Besides, the 'cultivated' genetic group is more likely to form a panmictic unit (all sites are in HW equilibrium and only rare pairs of loci in LD; Table 4). Conversely, the 'wild' genetic group displayed more evidence of substructuring-which was undetected using Bayesian clustering methods-larger global $F_{\mathrm{ST}}$ value, significant HW and LD as illustrated in Table 4. In addition, the variance in genetic and genotypic diversity indices is much greater across locations for the 'wild' group (Table 4). Six of the 21 comparisons of pairwise $F_{\mathrm{ST}}$ among the 'cultivated' group were significant $(P<0.05)$, whereas 21 pairs of sites of 28 comparisons were significantly different among the 'wild' group $(P<0.05)$. No IBD was detected among the 'cultivated' group $(P=0.85)$. Conversely, a significant positive correlation $(P=0.02)$ was detected between the $F_{\mathrm{ST}} /\left(1-F_{\mathrm{ST}}\right)$ values and geographical distances for individuals from the 'wild' group-a result consistent with the substructure evidenced above.

\section{Discussion}

\section{Regular spread of a poplar rust epidemic along} the Durance River valley

A major result of this study was demonstration of the spread of an annual rust epidemic along the Durance River valley. Monitoring the spatio-temporal occurrence

Table 4 Characteristics of the two genetic groups expressed as the means and ranges (in brackets) across sampling sites of several indices. Only sites with at least nine distinct genotypes were retained

\begin{tabular}{|c|c|c|c|c|c|c|c|c|}
\hline & $N_{\text {tot }}$ (range) & G/N (range) & $A_{r}$ (range) & $H_{\mathrm{E}}$ (range) & $H_{\mathrm{O}}$ (range) & $\bar{r}_{D}$ & $F_{\mathrm{IS}}$ & $F_{\mathrm{ST}}$ \\
\hline $\begin{array}{l}\text { Group } 1 \\
\text { ('Cultivated') (7 sites) }\end{array}$ & $19.3(9-31)$ & $0.78(0.45-1)$ & $2.65^{\mathrm{a}}(2.46-2.80)$ & $0.406^{\mathrm{b}}(0.388-0.436)$ & $0.400^{\mathrm{b}}(0.366-0.421)$ & $0.009^{* *}$ & $0.015^{\mathrm{a}}$ & $0.035^{* * * a}$ \\
\hline $\begin{array}{l}\text { Group } 2 \text { ('Wild') } \\
\text { (8 sites) }\end{array}$ & $28.2(9-47)$ & $0.83(0.23-1)$ & $2.95^{\mathrm{a}}(2.17-3.43)$ & $0.473^{\mathrm{a}}(0.393-0.507)$ & $0.455^{\mathrm{a}}(0.380-0.598)$ & $0.014^{* * *}$ & $0.039^{* * a}$ & $0.047^{* * * a}$ \\
\hline
\end{tabular}

$N_{\text {tot }}$ number of individuals assigned to each genetic groups; $G / N$, genotypic richness; $A r$, allelic richness (based on sample size of nine individuals); $H_{\mathrm{E}}$, expected heterozygosity; $H_{\mathrm{O}}$, observed heterozygosity; $\bar{r}_{D}$, multilocus estimate of linkage disequilibrium; $F-$ statistics $\left(F_{\mathrm{ST}}\right.$ and $\left.F_{\mathrm{IS}}\right)$ calculated according to Weir \& Cockerham (1984). Asterisks indicate the significance level of genetic disequilibrium and genetic structure ${ }^{* *} P$-value $<0.01$; ${ }^{* * *} P$-value $\left.<0.001\right)$. Letters indicate the results of group comparison tests (different letters indicate significant differences between 'wild' and 'cultivated' sites, $P<0.05$ ). 
(a)

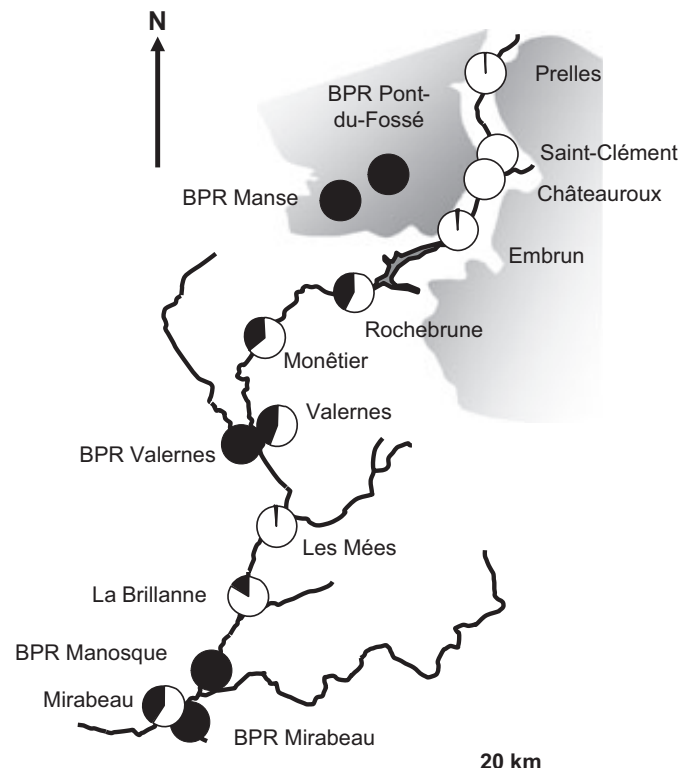

(b)

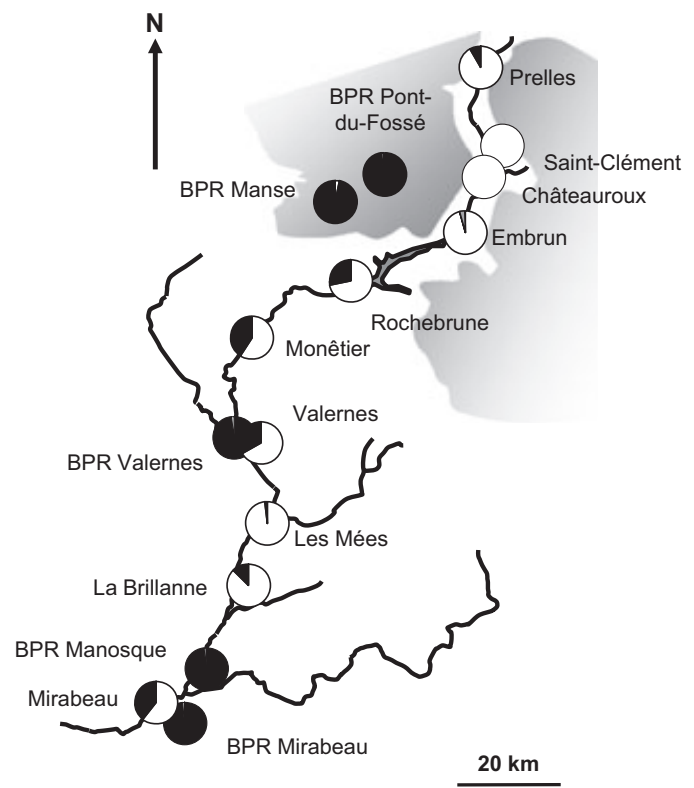

Fig. 5 (a) Geographical distribution of phenotypic profiles showing the proportions of Avr7 (white) and Vir7 (black) Melampsora larici-populina individuals at each site. (b) Geographical distribution of membership of the genetic groups, showing proportion of individuals assigned to the 'wild' (white), the 'cultivated' (black) and the hybrid (grey) groups at each site, according to the results of NewHYBRids.

of Melampsora larici-populina on poplar revealed that the epidemic began in the upstream part of the valley, where larches and poplars grow in sympatry, and then spread downstream to the area of allopatry. Due to the reliefs bordering the valley, the spread of M. laricipopulina is channelled along a one-dimensional corridor. These results again serve to highlight the importance of landscape features in the spread of plant diseases (Mundt et al. 2011).

Epidemiological data allowed the regular spread of the disease on both wild and cultivated poplar stands to be documented, revealing that the timing of first detection was earlier in cultivated stands than in neighbouring wild stands in the allopatry area. Because M. larici-populina individuals from cultivated stands can also infect wild poplar stands, the difference in the timing of infection is likely to result from differing ecological conditions in wild vs. cultivated stands. Indeed, cultivated stands are known to be more susceptible to disease (Prakash \& Thielges 1987; Chen \& Harrington 2006), which could favour detection.

The regular spread of the disease along the Durance River valley revealed by count data is in agreement with results from another host-alternating fungal pathogen: Puccinia sorghi (Zogg 1949). This latter study described accurately the spatio-temporal dynamics of a recurrent annual maize rust epidemic at that time in the higher Rhine River valley in Switzerland, over an 80-km-long transect. The alternate host, Oxalis stricta, was restricted to a small area of the studied transect, near Lake Constance. In 1945-1947, annual maize rust epidemics were shown to begin in this Maize-Oxalis sympatry area and then to spread regularly on maize along the Rhine River valley. As in the present study, knowledge of the location of the sympatry area between the two host plants enabled the starting point of the annual epidemics to be identified. However, the older study lacked a population genetics component, which in the present study allowed a better understanding of the epidemiological processes involved.

Interestingly, a major discrepancy was found in the regular spread of the disease on wild poplars, which challenges the view that there is a strictly gradual dispersal process for colonization of the Durance River valley. At Les Mées, the first rust symptoms were recorded very early, although this site is located far to the south of the sympatry area. A detailed examination of genotypic profiles revealed that these individuals belonged to the 'asexual' genetic group and that the most repeated genotype had also been sampled 5 years later in the southern part of the Durance River valley (Xhaard et al. 2011), suggesting a lack of sexual reproduction at that location. The most likely hypothesis for the early observation of poplar rust at Les Mées in 2004 is therefore that M. laricipopulina individuals overwintered asexually. Several authors have already suggested asexual overwintering 
in poplar rust fungi (Chiba \& Zinno 1960; Dupias 1965; Taris 1968; Walker et al. 1974; Wilkinson \& Spiers 1976; Pinon 1980), but the underlying survival mechanisms still need further investigation. This peculiar example provides a good illustration of how molecular tools can help unravel odd epidemiological patterns.

\section{Distinct genetic groups persist despite co-occurrence during an asexual epidemic}

In this study, the population genetics analysis of individuals provided additional insights into the genetic origin of the epidemic. A detailed Bayesian genetic assignment analysis found that $M$. larici-populina individuals collected after disease spread were clustered into two genetically distinct groups. Hence, this study provides evidence that cryptic population structure can be detected within the course of a single epidemic. It can be concluded that the poplar rust epidemic spreading southwards along the Durance River valley has in fact a dual inoculum source.

The distinction between the two genetic groups was highly robust and supported by the two Bayesian assignment algorithms (Structure and GenElAnd) used to assess the number of genetic clusters among the samples. The assignment profiles were very similar, although GENELAND appeared to be more efficient than the reference software STRUCTURE at assigning individuals to genetic groups. Such disparity between software is common (Durand et al. 2009) and results mostly from differences in algorithms, as these methods are not based on exact calculus (Rieux et al. 2011). The most important result is that this genetic partition accounts for the observed biological differences among the samples; there was a quasi-perfect match between phenotypic profiles and genetic group assignments. Moreover, although the two groups displayed close genetic characteristics, they differed significantly in their level of genetic diversity.

This genetic partition and the specificities of both genetic groups mirror the population structure observed in a previous study at a wider geographical scale (Xhaard et al. 2011). Based on their phenotypic and genotypic specificities, groups 1 and 2 were referred to as the 'cultivated' and the 'wild' group, respectively. Several lines of evidence indicate that individuals from the 'cultivated' group derive from a drastic selection event exerted by poplar cultivars, such as 'Beaupré', that carry the R7 rust resistance (Gérard et al. 2006). In particular, the 'cultivated' group consisted almost entirely of Vir7 individuals; moreover, this group was genetically less diverse than the 'wild' group. This latter characteristic is in accordance with the loss of heterozygosity that accompanies pathogen evolution on culti- vated crops (Burdon \& Thrall 2008; Gladieux et al. 2008), as a result of founder effects due to the limited number of individuals initially able to infect cultivars carrying qualitative resistance genes (Guérin et al. 2007). The 'wild' group exhibited a higher genetic diversity, consistent with long-standing co-evolution with the wild host.

Comparing the present results with those of Xhaard et al. (2011), it is noteworthy that the same partition of genetic variability and level of genetic differentiation was found among individuals sampled after a 5-year interval. The present study thus provides additional evidence that the 'wild' and 'cultivated' groups of M. larici-populina persist for years, despite co-occurrence during asexual epidemics, as observed on wild stands in the southern part of the Durance River valley.

\section{Which processes allow the persistence of genetic differentiation?}

In addition to confirming individual assignments, the use of a third assignment software (NEwHYBRIDS) permitted the quantification of hybridization events between 'wild' and 'cultivated' individuals. Overall, very few first-generation hybrids were found, although in many instances individuals from both groups cooccurred at the same location, especially in the southernmost part of the valley. These results stress the absence of hybridization between the two genetic groups, during both asexual epidemics and sexual reproduction in the sympatry area.

The lack of hybrids appearing during asexual epidemics can be interpreted in the light of the fungal life cycle plus information gleaned from disease monitoring. The southernmost sites of the valley are located far from the poplar-larch sympatry area where sexual reproduction takes place. As shown by Bourassa et al. (2007), the many asexual cycles that result in disease spread on the primary host are a dead-end process in the absence of an alternate host in the vicinity. In the following spring, the sexual spores resulting from meiosis (basidiospores) produced on dead poplar leaves can infect only larches in the immediate vicinity. Further downstream on the Durance River, individuals of M. larici-populina are too far away from the poplar-larch sympatry area and are thus very unlikely to contribute to sexual reproduction in the upstream region of the valley. Indeed, individuals from different genetic origins can co-occur in the same place, but as this co-occurrence takes place during asexual epidemics, they cannot hybridize. This illustrates how epidemiological knowledge informs more precise interpretation of genetic data. 
The lack of hybrids in the poplar-larch sympatry area is more puzzling. The presence of individuals of the 'cultivated' group in populations at Pont-du-Fossé and Manse rules out the hypothesis that these individuals cannot survive in the sympatry area. Moreover, the geographical distance between populations within the sympatry area is much shorter than the distance travelled by the epidemic wave in one season. Nonetheless, a clear split in the spatial distribution of the two genetic entities was observed in this area, with no individual from the 'wild' group in the western part of the sympatry area, and a quasi-absence of individuals from the 'cultivated' group in the eastern part, further upstream on the Durance River. Individuals from these two foci were sampled from different host plants but, as previously discussed, this cannot account for the observed genetic differentiation and the lack of gene flow as individuals from the 'cultivated' group can infect wild poplars. The most likely hypothesis to account for this spatial genetic structure is that the sympatry area is a contact zone between the two genetic groups, with 'cultivated' genotypes invading the native 'wild' distribution area from the northwest (Xhaard et al. 2011). A large mountain range splits this spatial domain, which might shelter 'wild' genotypes from hybridization or at least slow down the invasion of the 'cultivated' genotypes. Unfortunately, this hypothesis cannot be tested using this data set, and a new dedicated study with extensive sampling in the sympatry area (i.e. a landscape genetic approach) will be required to further decipher local barriers to gene flow.

Taken together, these results confirm that epidemiological studies aiming to infer dispersal capacities during epidemics can benefit from molecular epidemiology data. Unlike demographic quantification only (Zogg 1949), the use of molecular data allows a refined characterization of the inoculum source in the sympatry area. The population genetics analyses performed in this study clearly show that epidemic spread along the Durance River originates from two inoculum sources located in the poplarlarch sympatry area. Individuals of both 'cultivated' and 'wild' groups then disperse asexually southwards along the Durance River, giving rise to a single but genetically heterogeneous poplar rust epidemic. In the allopatry area, individuals belonging to both genetic groups became mixed on wild Populus nigra stands. The ability to track individuals from the two sources throughout the annual epidemic opens the prospect of refining inference of dispersal by following separately the contributions from the two potential inoculum sources.

\section{Genetic consequences of disease spread}

Epidemiology and population genetics approaches also supplement the study of the genetic consequences of demographic fluctuations associated with colonization events during disease spread. Each group detected after Bayesian assignment analysis forms a quasi-panmictic unit, but nonetheless some traces of substructuring were found within both 'wild' and 'cultivated' groups (positive $F_{\mathrm{IS}}$ and significant LD across locations). These traces of genetic disequilibria are very likely to result from demographic changes accompanying disease spread, as found at higher spatial scales in other plant pathogenic fungi (Zeller et al. 2004; Halkett et al. 2010). In a continental study of the genetic diversity of the North American poplar rust fungus Melampsora medusae f. sp. deltoidae, Bourassa et al. (2007) showed that the genetic diversity was higher in the poplar-larch sympatry area (Great Lakes Region, Ontario and Quebec) than in an area with poplars only (most of the eastern United States). The genetic features of poplar rust individuals collected in the allopatry area suggested that they resulted from annual asexual spread of individuals originating from sexual populations in the poplar-larch sympatry area (Bourassa et al. 2007). The same result, contrasting the genetic signatures of individuals from the sympatry vs. allopatry areas, was found here. Moreover, unlike the case of Bourassa et al. (2007), M. larici-populina individuals were sampled here along the entire epidemiological transect. This study thus provides additional details of the genetic structure resulting from an epidemic spread. A significant correlation between genetic and geographical distances was found among individuals from the 'wild' group. This spatial genetic structure is consistent with a gradual dispersal pattern (Slatkin 1985; Leblois et al. 2004; Barrès et al. 2008) resulting from the observed colonization dynamics (Halkett et al. 2010). In addition to deciphering the genetic origins of M. larici-populina individuals collected at the end of a poplar rust epidemic, this population genetics analysis also allowed us to confirm the gradual dispersal process responsible for the spread of disease along the Durance River. Because the source of the populations and the path followed by the epidemic wave can be identified clearly, the Durance River valley constitutes a unique ecological system in which to examine further the genetic consequences of dispersal by combining population genetics and epidemiological data in more detailed spatio-temporal surveys.

\section{Concluding remarks: strengths of combining epidemiology and population genetics}

The many population genetics studies on fungal plant pathogens in the literature have tackled a wide array of evolutionary questions. However, gaps between plant pathogen epidemiology and population genetics studies still remain, and there is a paucity of work aiming to 
combine these disciplines (Milgroom 2001; Archie et al. 2009). Most of the difficulties stem from differences in the spatial or temporal scales considered. Yet these two disciplines are tightly interconnected because neutral genetic structures derive mostly from the balance between migration and genetic drift, both of which rely on demographic processes. The main originality of this study is that the same ecological system was analysed from both an epidemiological and a population genetics point of view. This molecular epidemiology approach allowed us to append information from both data sets, and hence exceeded the limits of each separate discipline towards achieving a better understanding of this biological system. These data serve to illustrate the strength of combining epidemiology and population genetics data sets. The availability of highly polymorphic and reliable molecular markers, together with the advent of Bayesian clustering methods, allows cryptic population genetic structures to be revealed. As seen here, large genetic units can persist for years in spite of being sometimes locally admixed. It is thus possible to define 'true' pathogen populations with contrasting evolutionary histories that could serve as management units in crop protection strategies. The methods employed here can define the genetic origin and retrace the colonization history and migration pathways of a recent epidemic. In addition, such detailed analysis of the very fine population genetic structure provides insights into the genetic consequences of contemporaneous demographic events. The Durance River valley therefore represents an ecological system all the more suited to the study of dispersal processes in a plant pathogen. In this respect, this specific ecological scenario will contribute to a better understanding of the evolutionary forces at work during biological invasion or the spread of emerging disease.

\section{Acknowledgements}

This research was supported by grants from ECOGER (AIP 00295-298, INTERPOPGER program), the Agence Nationale de la Recherche (ANR 07-BDIV-003, EMERFUNDIS program) and INRA (projet innovant EFPA). C.X. and B.B. were supported by $\mathrm{PhD}$ fellowships from the French Ministry of Education and Research (MESR) and the Région Lorraine, respectively. We would like to thank Béranger Bertin and Christine Géhin for their technical help, Cyril Dutech, Jérôme Enjalbert, Frédéric Fabre, Etienne Klein and Jean Pinon for fruitful discussions, two anonymous reviewers for their valuable comments and suggestions, and Helen Rothnie for her careful English language checking.

\section{References}

Agapow PM, Burt A (2001) Indices of multilocus linkage disequilibrium. Molecular Ecology Notes, 1, 101-102.
Agrios GN (2005) Plant Pathology. Elsevier Academic Press, Oxford.

Anderson EC, Thompson EA (2002) A model-based method for identifying species hybrids using multilocus genetic data. Genetics, 160, 1217-1229.

Archie EA, Luikart G, Ezenwa VO (2009) Infecting epidemiology with genetics: a new frontier in disease ecology. Trends in Ecology \& Evolution, 24, 21-30.

Barrès B, Dutech C, Andrieux A, Caron H, Pinon J, Frey P (2006) Isolation and characterization of 15 microsatellite loci in the poplar rust fungus, Melampsora larici-populina, and cross-amplification in related species. Molecular Ecology Notes, 6, 60-64.

Barrès B, Halkett F, Dutech C, Andrieux A, Pinon J, Frey P (2008) Genetic structure of the poplar rust fungus Melampsora larici-populina: evidence for isolation by distance in Europe and recent founder effects overseas. Infection, Genetics and Evolution, 8, 577-587.

Barrett LG, Thrall PH, Burdon JJ, Linde CC (2008) Life history determines genetic structure and evolutionary potential of host-parasite interactions. Trends in Ecology \& Evolution, 23, 678-685.

Belkhir K, Borsa P, Chikhi L, Raufaste N, Bonhomme F (19962004) GENETIX 4.05, logiciel sous Windows TM pour la génétique des populations. Laboratoire Génome, Populations, Interactions, CNRS UMR 5171, Université de Montpellier II, Montpellier, France.

Benjamini Y, Yekutieli D (2001) The control of the false discovery rate in multiple testing under dependency. Annals of Statistics, 29, 1165-1188.

Bourassa M, Bernier L, Hamelin RC (2007) Genetic diversity in poplar leaf rust (Melampsora medusae f. sp deltoidae) in the zones of host sympatry and allopatry. Phytopathology, 97, 603-610.

Bucheli E, Gautschi B, Shykoff JA (2001) Differences in population structure of the anther smut fungus Microbotryum violaceum on two closely related host species, Silene latifolia and S. dioica. Molecular Ecology, 10, 285-294.

Burdon JJ, Thrall PH (2008) Pathogen evolution across the agro-ecological interface: implications for disease management. Evolutionary Applications, 1, 57-65.

Burdon JJ, Jarosz AM, Kirby GC (1989) Pattern and patchiness in plant-pathogen interactions - causes and consequences. Annual Review of Ecology and Systematics, 20, 119-136.

Carlier J, Lebrun MH, Zapater MF, Dubois C, Mourichon X (1996) Genetic structure of the global population of banana black leaf streak fungus, Mycosphaerella fijiensis. Molecular Ecology, 5, 499-510.

Chen W, Harrington TC (2006) Genetic diversity of poplar leaf rust populations in the north-central United States. Canadian Journal of Forest Research, 36, 2047-2057.

Chiba O, Zinno Y (1960) Uredospores of the poplar leaf rust, Melampsora larici-populina Kleb., as a source of primary infection. Journal of the Japanese Forestry Society, 42, 406410.

Criscione CD, Poulin R, Blouin MS (2005) Molecular ecology of parasites: elucidating ecological and microevolutionary processes. Molecular Ecology, 14, 2247-2257.

Criscione CD, Vilas R, Paniagua E, Blouin MS (2011) More than meets the eye: detecting cryptic microgeographic population structure in a parasite with a complex life cycle. Molecular Ecology, 20, 2510-2524. 
Dupias G (1965) Les rouilles des peupliers dans les Pyrénées et le bassin sous-pyrénéen. Bulletin de la Société Mycologique de France, 81, 188-196.

Durand E, Jay F, Gaggiotti OE, Francois O (2009) Spatial inference of admixture proportions and secondary contact zones. Molecular Biology and Evolution, 26, 1963-1973.

Estoup A, Guillemaud T (2010) Reconstructing routes of invasion using genetic data: why, how and so what? Molecular Ecology, 19, 4113-4130.

Evanno G, Regnaut S, Goudet J (2005) Detecting the number of clusters of individuals using the software STRUCTURE: a simulation study. Molecular Ecology, 14, 2611-2620.

Falush D, Stephens M, Pritchard JK (2003) Inference of population structure using multilocus genotype data: linked loci and correlated allele frequencies. Genetics, 164, 1567-1587.

Flor HH (1971) Current status of the gene-for-gene concept. Annual Review of Phytopathology, 9, 275-296.

Frey P, Gérard PR, Feau N, Husson C, Pinon J (2005) Variability and population biology of Melampsora rusts on poplars. In: Rust Diseases of Willow and Poplar (eds Pei MH, McCracken AR), pp. 63-72. CAB International, Wallingford, UK.

Gérard PR, Husson C, Pinon J, Frey P (2006) Comparison of genetic and virulence diversity of Melampsora larici-populina populations on wild and cultivated poplar and influence of the alternate host. Phytopathology, 96, 1027-1036.

Gladieux P, Zhang XG, Afoufa-Bastien D, Sanhueza RMV, Sbaghi M, Le Cam B (2008) On the origin and spread of the scab disease of apple: out of Central Asia. PLoS ONE, 3, e1455.

Gladieux P, Zhang XG, Roldan-Ruiz I et al. (2010) Evolution of the population structure of Venturia inaequalis, the apple scab fungus, associated with the domestication of its host. Molecular Ecology, 19, 658-674.

Gómez-Alpizar L, Carbone I, Ristaino JB (2007) An Andean origin of Phytophthora infestans inferred from mitochondrial and nuclear gene genealogies. Proceedings of the National Academy of Sciences, 104, 3306-3311.

Goudet J (1995) FSTAT (Version 1.2): a computer program to calculate F-statistics. Journal of Heredity, 86, 485-486.

Guérin F, Gladieux P, Le Cam B (2007) Origin and colonization history of newly virulent strains of the phytopathogenic fungus Venturia inaequalis. Fungal Genetics and Biology, 44, 284-292.

Guillot G (2008) Inference of structure in subdivided populations at low levels of genetic differentiation - the correlated allele frequencies model revisited. Bioinformatics, 24, 2222-2228.

Guillot G, Estoup A, Mortier F, Cosson JF (2005a) A spatial statistical model for landscape genetics. Genetics, 170, 12611280.

Guillot G, Mortier F, Estoup A (2005b) GENELAND: a computer package for landscape genetics. Molecular Ecology Notes, 5, 712-715.

Halkett F, Coste D, Platero GGR, Zapater MF, Abadie C, Carlier J (2010) Genetic discontinuities and disequilibria in recently established populations of the plant pathogenic fungus Mycosphaerella fijiensis. Molecular Ecology, 19, 39093923.

Holdenrieder O, Pautasso M, Weisberg PJ, Lonsdale D (2004) Tree diseases and landscape processes: the challenge of landscape pathology. Trends in Ecology \& Evolution, 19, 446-452.
Hovmøller MS, Yahyaoui AH, Milus EA, Justesen AF (2008) Rapid global spread of two aggressive strains of a wheat rust fungus. Molecular Ecology, 17, 3818-3826.

Imbert E, Lefevre F (2003) Dispersal and gene flow of Populus nigra (Salicaceae) along a dynamic river system. Journal of Ecology, 91, 447-456.

Kaeuffer R, Reale D, Coltman DW, Pontier D (2007) Detecting population structure using STRUCTURE software: effect of background linkage disequilibrium. Heredity, 99, 374-380.

Kauserud H, Svegarden IB, Saetre GP et al. (2007) Asian origin and rapid global spread of the destructive dry rot fungus Serpula lacrymans. Molecular Ecology, 16, 3350-3360.

Leblois R, Rousset F, Estoup A (2004) Influence of spatial and temporal heterogeneities on the estimation of demographic parameters in a continuous population using individual microsatellite data. Genetics, 166, 1081-1092.

Legionnet A, Muranty H, Lefevre F (1999) Genetic variation of the riparian pioneer tree species Populus nigra. II. Variation In susceptibility to the foliar rust Melampsora larici-populina. Heredity, 82, 318-327.

de Meeûs T, McCoy KD, Prugnolle F et al. (2007) Population genetics and molecular epidemiology or how to "debusquer la bete". Infection, Genetics and Evolution, 7, 308-332.

Milgroom MG (2001) The synthesis of genetics and epidemiology: contribution of population biology in plant pathology. Journal of Plant Pathology, 83, 57-62.

Milgroom MG, Peever TL (2003) Population biology of plant pathogens: the synthesis of plant disease epidemiology and population genetics. Plant Disease, 87, 608-617.

Mundt CC, Sackett KE, Wallace LD (2011) Landscape heterogeneity and disease spread: experimental approaches with a plant pathogen. Ecological Applications, 21, 321-328.

Munkacsi AB, Stoxen S, May G (2008) Ustilago maydis populations tracked maize through domestication and cultivation in the Americas. Proceedings of the Royal Society B-Biological Sciences, 275, 1037-1046.

Nei M (1978) Estimation of average heterozygosity and genetic distance from a small number of individuals. Genetics, 89, 583-590.

Ostfeld RS, Glass GE, Keesing F (2005) Spatial epidemiology: an emerging (or re-emerging) discipline. Trends in Ecology $\mathcal{E}$ Evolution, 20, 328-336.

Pinon J (1980) Etude de la survie des urédospores de Melampsora larici-populina Kleb. et de M. allii-populina Kleb. Annales des Sciences Forestières, 37, 85-89.

Pinon J, Frey P (1997) Structure of Melampsora larici-populina populations on wild and cultivated poplar. European Journal of Plant Pathology, 103, 159-173.

Pinon J, Frey P (2005) Interactions between poplar clones and Melampsora larici-populina populations and their implications for breeding for durable resistance. In: Rust Diseases of Willow and Poplar (eds Pei MH, McCracken AR), pp. 139-154. CAB International, Wallingford, UK.

Plantegenest M, Le May C, Fabre F (2007) Landscape epidemiology of plant diseases. Journal of The Royal Society Interface, 4, 963-972.

Prakash CS, Thielges BA (1987) Pathogenic variation in Melampsora medusae leaf rust of poplars. Euphytica, 36, 563-570.

Pritchard JK, Stephens M, Donnelly P (2000) Inference of population structure using multilocus genotype data. Genetics, 155, 945-959. 
Rieux A, Halkett F, de Lapeyre de Bellaire L et al. (2011) Inferences on pathogenic fungus population structures from microsatellite data: new insights from spatial genetics approaches. Molecular Ecology, 20, 1661-1674.

Riou-Nivert P (2001) Le mélèze. Institut pour le Développement Forestier, Paris, pp. 144.

Rousset F (2000) Genetic differentiation between individuals. Journal of Evolutionary Biology, 13, 58-62.

Rousset F (1997) Genetic differentiation and estimation of gene flow from $F$-Statistics under isolation by distance. Genetics, 145, 1219-1228.

Rousset F (2008) GENEPOP'007: a complete re-implementation of the GENEPOP software for Windows and Linux. Molecular Ecology Resources, 8, 103-106.

Slatkin M (1985) Gene flow in natural populations. Annual Review of Ecology and Systematics, 16, 393-430.

Stenberg P, Lundmark M, Saura A (2003) MLGsim: a program for detecting clones using a simulation approach. Molecular Ecology Notes, 3, 329-331.

Storey JD, Tibshirani R (2003) Statistical significance for genomewide studies. Proceedings of the National Academy of Sciences of the United States of America, 100, 9440-9445.

Stukenbrock EH, Banke S, Javan-Nikkhah M, McDonald BA (2007) Origin and domestication of the fungal wheat pathogen Mycosphaerella graminicola via sympatric speciation. Molecular Biology and Evolution, 24, 398-411.

Taris B (1968) Contribution à l'étude des rouilles des Populus observées en France. Annales des Epiphyties, 19, 5-54.

Vaha JP, Primmer CR (2006) Efficiency of model-based Bayesian methods for detecting hybrid individuals under different hybridization scenarios and with different numbers of loci. Molecular Ecology, 15, 63-72.

Van Oosterhout C, Hutchinson WF, Wills DPM, Shipley P (2004) MICRO-CHECKER: software for identifying and correcting genotyping errors in microsatellite data. Molecular Ecology Notes, 4, 535-538.

Walker J, Hartigan D, Bertus AL (1974) Poplar rusts in Australia with comments on potential conifer rusts. European Journal of Forest Pathology, 4, 100-118.

Wang IJ (2010) Recognizing the temporal distinctions between landscape genetics and phylogeography. Molecular Ecology, 19, 2605-2608.

Waples RS, Gaggiotti O (2006) What is a population? An empirical evaluation of some genetic methods for identifying the number of gene pools and their degree of connectivity. Molecular Ecology, 15, 1419-1439.
Weir BS, Cockerham CC (1984) Estimating F-statistics for the analysis of population structure. Evolution, 38, 1358-1370.

Wilkinson AG, Spiers AG (1976) Introduction of poplar rusts Melampsora larici-populina and Melampsora medusae to NewZealand and their subsequent distribution. New Zealand Journal of Science, 19, 195-198.

Xhaard C, Andrieux A, Halkett F, Frey P (2009) Characterization of 41 microsatellite loci developed from the genome sequence of the poplar rust fungus, Melampsora larici-populina. Conservation Genetics Resources, 1, 21-25.

Xhaard C, Fabre B, Andrieux A et al. (2011) The genetic structure of the plant pathogenic fungus Melampsora laricipopulina on its wild host is extensively impacted by host domestication. Molecular Ecology, 20, 2739-2755.

Zaffarano PL, McDonald BA, Linde CC (2008) Rapid speciation following recent host shifts in the plant pathogenic fungus Rhynchosporium. Evolution, 62, 1418-1436.

Zeller KA, Bowden RL, Leslie JF (2004) Population differentiation and recombination in wheat scab populations of Gibberella zeae from the United States. Molecular Ecology, 13, 563-571.

Zogg Z (1949) Untersuchungen über die Epidemiologie des Maisrostes Puccinia sorghi Schw. Phytopathologische Zeitschrift, 15, 143-192.

This study forms part of the PhD research of C.X., which addressed the gene flow between populations of Melampsora larici-populina and the genetic consequences of dispersal, and of B.B., who studied the inference of dispersal processes in M. larici-populina. A.A. is in charge of the molecular techniques used for fungus genotyping. L.B. is an epidemiologist interested in pathogen transmission in relation to adaptation of populations to plant resistances. F.H. is a population biologist interested in the population genetics and evolutionary biology of fungal plant pathogens. P.F. has a long-standing knowledge of the biology and genetics of rust fungi.

\section{Data accessibility}

Microsatellite data (470 individuals genotyped): data deposited in the Dryad repository: doi: 10.5061/dryad.249kj74s. 